\title{
Desenvolvimento, espaço e crise estrutural
}

Development, space and structural crisis

Développement, espace et crise structurelle

\section{Maurilio Lima Botelho}

\section{(2) OpenEdition}

Journals

Edição electrónica

URL: http://journals.openedition.org/espacoeconomia/153

DOI: 10.4000/espacoeconomia.153

ISSN: 2317-7837

Editora

Núcleo de Pesquisa Espaço \& Economia

Refêrencia eletrónica

Maurilio Lima Botelho, « Desenvolvimento, espaço e crise estrutural », Espaço e Economia [Online],

2 | 2013, posto online no dia 09 março 2013, consultado o 03 maio 2019. URL : http://

journals.openedition.org/espacoeconomia/153 ; DOI : 10.4000/espacoeconomia.153

Este documento foi criado de forma automática no dia 3 Maio 2019

(C) NUPEE 


\title{
Desenvolvimento, espaço e crise estrutural
}

\author{
Development, space and structural crisis \\ Développement, espace et crise structurelle
}

\section{Maurilio Lima Botelho}

1 Embora todos os três temas indicados no título desse artigo sejam de difícil formulação, uma definição inicial de desenvolvimento pode permitir o desdobramento de uma reflexão sobre o espaço e, em seguida, sobre crise. Numa concepção um tanto abrangente, podemos definir o desenvolvimento a partir das condições básicas da sociedade capitalista, ou melhor, partir das condições em que é possível se falar em desenvolvimento na sociedade capitalista.

2 Em um livro que hoje está quase esquecido, mas que foi considerado uma espécie de livrotexto por pelo menos duas gerações, Paul Sweezy abordou o problema geral do desenvolvimento no capitalismo. Com o título de A teoria do desenvolvimento capitalista, essa obra, publicada em 1942, tentava apresentar - seguindo principalmente o debate no interior do marxismo e tentando responder aos críticos do marxismo - o funcionamento da economia capitalista (SWEEZY, 1983). A partir da discussão sobre valor, trabalho abstrato e esquemas de reprodução, entre outros temas, Sweezy apresentava os princípios que regem a acumulação de capital. $\mathrm{O}$ desenvolvimento capitalista ocorre a partir do momento em que a produção em expansão cria um mercado consumidor e, realizando-se neste a mais-valia gerada naquela (na produção), há a reprodução ampliada de capital. Não sem fricções e com uma série de problemas que se amplificam em termos lógicos e temporais, o desenvolvimento capitalista significa basicamente (1) expansão crescente da produção, (2) ampliação do mercado e, como resultado da articulação entre esses dois pressupostos, (3) acumulação de capital.

3 Partindo dessa definição, podemos falar em desenvolvimento em geral no capitalismo. Como é óbvio, isso não define ou explica casos específicos, como o desenvolvimento nacional ou o desenvolvimento regional, mas é uma condição para o desenvolvimento 
nessas escalas. Sobre isso, aliás, uma das discussões mais famosas do final do século XX não por acaso esbarrou na definição geral de desenvolvimento ao tratar de um caso nacional. $\mathrm{O}$ debate sobre o avanço do capitalismo na Rússia foi abordado por Lênin numa obra que talvez seja um dos melhores exemplos de estudo do desenvolvimento capitalista em condições nacionais. Em O Desenvolvimento do capitalismo na Rússia, o líder comunista russo argumentou que o capitalismo não apenas era viável na Rússia, como este já estava se desenvolvendo porque os investimentos capitalistas estavam produzindo um mercado interno e rompendo definitivamente com os laços feudais (LÊNIN, 1982). A chave para a resposta ao problema do desenvolvimento capitalista era a formação do mercado: a produção em expansão levava à formação de um mercado e isso possibilitaria a acumulação de capital no interior do território do Czar.

Um outro exemplo é um estudo publicado por José Serra, no início da década de 1980, em que avalia que o capitalismo brasileiro adquiriu um grau de maturidade após a produção interna de bens de capital nos últimos anos do milagre econômico, isto é, a internalização de parte do Departamento I (SERRA, 1982). O artigo de Serra defendia que, apesar da maturidade de nossa produção e de sua expansão (a ponto de provocar capacidade ociosa em diversos setores), o declínio do crescimento econômico a partir de 1974 se devia a uma restrição no mercado consumidor, principalmente de bens de consumo. 0 desenvolvimento econômico travado se devia a uma dificuldade de completar esses princípios básicos em que a expansão da produção é acompanhada de uma ampliação do mercado.

Até aqui foram discutidas apenas as condições para o desenvolvimento econômico na sociedade capitalista. O que o espaço tem a ver com isso?

6 A resposta é muito clara: uma das condições básicas para o desenvolvimento econômico a ampliação dos mercados - tem claramente uma natureza espacial. Poderíamos inclusive especificar: existem dois modos espacialmente diferenciados de ampliação dos mercados.

7 De um lado temos a expansão geográfica do capitalismo, que poderíamos chamar de expansão externa dos mercados. A outra forma de expansão seria a criação de novos produtos, novas mercadorias, inovações no mercado, portanto a expansão interna dos mercados. Poderíamos chamar essa segunda forma de expansão interna do capitalismo ou intensificação do capitalismo. As duas maneiras de se expandir os mercados têm uma natureza espacial muito evidente.

8 A expansão externa representa a expansão absoluta da sociedade capitalista e, portanto, do mercado capitalista, ampliando o horizonte geográfico de sua atuação. A teoria que abordou com mais ênfase esse caráter expansivo externo foi a teoria do imperialismo de Rosa Luxemburgo (LUXEMBURGO, 1984). Embora equivocado em seus princípios teóricos, o argumento da socialista alemã era que o capitalismo só se mantém graças a uma expansão geográfica constante, uma ampliação progressiva de suas fronteiras através da incorporação sucessiva de sociedades não-capitalistas. Dado que o capital é por natureza a produção de excedente, a única maneira de realizar esse excedente seria encontrando mercados no exterior. O capitalismo só pode existir com a condição de se ampliar progressivamente para além de si mesmo. Ora, há uma série de problemas aí que abriram um longo debate, por exemplo: como encontrar mercados externos se o mercado é um princípio de socialização tipicamente moderno, se o mercado em outras sociedades não existia ou era marginal, limitado? Não fica claro também como é possível que as sociedades externas comprem as mercadorias produzidas pelo capitalismo - de onde vem esse dinheiro? Apesar de todos os problemas, é interessante que a expansão geográfica do 
capitalismo aparece não como o resultado da sua dinâmica, mas como uma necessidade para a sua manutenção.

9 Uma outra leitura, um pouco mais rigorosa, é a teoria clássica do imperialismo, cujos representantes são Hilferding, Bukharin e Lênin (HILFERDING, 1980; BUKHARIN, 1986; LÊNIN, 2011). ${ }^{1}$ Apesar das diferenças entre eles, o centro do argumento desses autores é que o capitalismo atingiu um grau de maturidade que passa a ter problemas de suparacumulação - a solução desse problema é a busca de novos campos para o investimento e para desaguar o capital excedente. 0 capitalismo não busca mercados externos, o capitalismo produz esses mercados. A fronteira capitalista é a fronteira onde se produz um espaço típico para o capital, isto é, onde se inicia o processo de expropriação dos meios de produção, investimento, produção de mercadorias e criação de mercado consumidor. $\mathrm{O}$ imperialismo é a tentativa de escoar o capital excedente europeu no final do século XIX, seja através de empréstimos para os novos países da América Latina, seja através da corrida pelas colônias africanas, seja através da imposição de normas de consumo e produtos aos impérios asiáticos. Para usar os termos de David Harvey, o capital precisa produzir um novo espaço para se fixar ou se ajustar (spatial fix). O capitalismo dribla seus problemas internos através da exteriorização de sua dinâmica. A afirmação já se tornou banal, mas não deixa de ser verdadeira: o capital contém em seu interior uma tendência à globalização com essa expansão geográfica absoluta.

Por outro lado, como foi dito, temos a expansão interna do capitalismo. O que vem a ser isso? Como o desenvolvimento capitalista necessita da criação de mercados para receber a produção crescente, é preciso criar novos nichos de mercado, novas mercadorias, novos produtos. Além do impulso para a expansão externa, é preciso transformar tudo que resta no interior dessa formação social em mercadoria e, mais ainda, é preciso desenvolver novas mercadorias para que os mercados se intensifiquem progressivamente. Poderíamos chamar essa expansão interna de reestruturação, o que implica tanto a reformulação de produtos quanto a reestruturação produtiva propriamente dita, isto é, inovar tanto no mercado de bens de consumo quanto no mercado de meios de produção. Inovar constantemente na esfera da produção e na esfera do consumo.

11 Aqui também nos defrontamos com uma natureza espacial muito clara, pois reestruturação significa constantemente reorganização espacial, modificação de plantas fabris, progresso em transportes e telecomunicações, construção e reconstrução de infraestrutura urbana etc. Por isso essa expansão é uma intensificação - é como se o capitalismo potencializasse as condições de produção já dadas. É possível dizer, deste modo, que além de uma expansão geográfica absoluta há uma expansão geográfica relativa, ou um "vai-e-vem do capital", segundo a boa expressão de Neil Smith (SMITH, 1988, p.191-219).

Temos aqui uma maneira de encarar a relação entre desenvolvimento e espaço: para viabilizar o desenvolvimento econômico, isto é, a expansão da produção e ampliação de mercados, é preciso uma expansão geográfica externa, uma reestruturação interna ou a combinação das duas. O desenvolvimento econômico capitalista só pode ser obtido por meio da "expansão ou da reestruturação geográfica" (HARVEY, 2006, p.142).

13 Contudo, já que começamos discutindo o desenvolvimento econômico a partir de uma obra de Paul Sweezy, esse mesmo autor escreveu uma carta em 1987 para um intelectual europeu, seu amigo. Nessa carta, Paul Sweezy fazia uma avaliação do estágio alcançado pelo desenvolvimento capitalista e atestava que este se encontrava num ponto de inflexão: 
"Hoje o processo de acumulação do capital, que é e sempre foi força motriz última do desenvolvimento capitalista, se atolou no lamaçal profundo da estagnação (...). o que se pode razoavelmente esperar (...) é um longo futuro de aprofundamento da crise capitalista irreversível". ${ }^{2}$ para expansão capitalista - a unificação do mundo pelo mercado chegou ao fim. Ainda que possa existir uma ou outra área do planeta ainda não totalmente incorporada ao mundo da mercadoria e do dinheiro, a dimensão dessas áreas não é suficiente para resgatar o capitalismo e colocá-lo num novo ciclo de expansão. Assim, o capitalismo chegou ao seu limite de expansão geográfica externa: não há mais possibilidade de criar um novo mercado externo para salvá-lo dessa condição crítica. A globalização representa, portanto, o ápice desse processo de expansão geográfica externa, para além do qual não há mais exterioridade. Isso tem uma série de implicações ainda, inclusive em termos ecológicos (externalização de custos) e econômicos (formação de um mercado de força de trabalho mundial unificado), mas destaquemos esse limite geográfico importante: não há mais saída externa para a expansão dos mercados. Se há superacumulação de capital ou superacumulação de mercadorias, não é possível mais escoar para fora o excedente realizado no passado.

17 A segunda limitação geográfica ao desenvolvimento capitalista é mais complexa, mas é também a mais significativa de todas: é possível ainda para o capitalismo passar por reestruturações, portanto, realizar reconfigurações espaciais, reformulação produtiva ou inovações em produtos. Mas há aqui um dado novo no próprio processo de reestruturação: o capitalismo atingiu um tal grau de produtividade, graças ao desenvolvimento tecnológico, que hoje a expansão da produção não é acompanhada pela ampliação de mercados.

a, como indicado, um dos princípios do desenvolvimento capitalista é que, para ocorrer reprodução ampliada, acumulação de capital, é preciso que a expansão da produção seja acompanhada pela expansão do mercado. A própria produção capitalista em termos gerais se encarrega disso: a expansão capitalista representa produção de força de trabalho assalariada e, assim, criação de mercado consumidor. o problema é que isso não é mais um princípio para o capitalismo contemporâneo.

Os teóricos e especialistas em tecnologia e economia industrial têm chamado a atenção para esse fato novo gerado pela microeletrônica e pela informática: a velocidade de racionalização da produção supera a velocidade de expansão dos mercados. Isso significa que há uma incompatibilidade entre um lado e outro da balança capitalista. Em termos microeconômicos podemos dizer que a velocidade de inovação dos processos é maior que a velocidade de inovação dos produtos. ${ }^{3}$ A produção passa constantemente por reestruturações e inovações produtivas, mas os produtos e mercados consumidores são basicamente os mesmos ou se alteram muito pouco. Em termos macroeconômicos isso significa que a taxa 
de produtividade é maior que a taxa de crescimento econômico, ou seja, chegamos a um nível de expulsão absoluta de trabalhadores do processo produtivo. Há um termo que os economistas usam para definir esse momento novo na história do capitalismo - jobless growth, ou seja, crescimento sem emprego ${ }^{4}$ (ALBAN, 1999). Crescimento econômico não representa necessariamente geração de emprego, na verdade pode até representar o contrário, dadas as inovações produtivas constantes e o incremento na produtividade.

Portanto, o capitalismo não tem mais capacidade de fazer o mercado seguir a produção e isso não é absolutamente um objetivo estranho a uma sociedade que sempre perseguiu a produção pela produção. O fim em si mesmo da produção capitalista nos levou a uma condição em que não é possível mais desenvolvimento nos marcos do capitalismo - o capitalismo atravessa uma crise estrutural.

21 Aqui é necessário um pouco de cuidado: impossibilidade de desenvolvimento econômico, crise estrutural ou "crise irreversível" - tal como apontado por Paul Sweezy -, não significa absolutamente o fim do capitalismo, que a sociedade burguesa vai acabar no virar da noite ou que estamos chegando ao dia do juízo final. Crise estrutural é um termo adequado que afasta essas interpretações etapistas: crise estrutural significa que o capitalismo não tem mais condições de apresentar um novo ciclo global de expansão, não pode entrar mais em uma nova fase expansiva ou, para ser mais claro, terminou a "fase de ascensão histórica do capitalismo". ${ }^{5}$

Desde a crise da década de 1970 o capitalismo não foi mais capaz de apresentar um novo ciclo de expansão - mesmo a descrição da dinâmica capitalista em termos de ciclos não é mais válida, a não ser que estejamos nos referindo aos ciclos de bolhas especulativas. Dizer isso significa dizer que um ou outro país não possa crescer ou mesmo gerar empregos, mas esse crescimento é pontual, individualizado e deve ter explicações específicas - o que significa também que, em geral, mesmo essa geração de emprego pode ocorrer através da substituição de força de trabalho em outras regiões, pois o caso chinês é muito explícito quanto a isso.

Assim entramos em outro desdobramento dessa discussão que é importante para impedir compreensões errôneas - a irrupção da crise estrutural não significa que o capitalismo parou de funcionar. Na verdade, dados os limites do desenvolvimento econômico, o capital encontrou expedientes para administrar a crise, podemos dizer que o capitalismo pratica uma "fuga para a frente". Já que a forma principal da crise no capitalismo é sempre crise de suparacumulação, o mercado de capitais oferece uma oportunidade para desenvolver mecanismos que simulem o crescimento econômico. A ficcionalização do capital, a financeirização recente ou a "economia de bolhas", para usar uma expressão de Robert Brenner (BRENNER, 2003), não é a causa da crise econômica que enfrentamos hoje - é na verdade uma das formas de aliviar os seus efeitos. É evidente que sempre que as bolhas explodem, os efeitos contidos surgem mais violentamente, mas esse é o resultado de uma sociedade que, na falta de mercados, simula mercados através do endividamento e da ficcionalização.

Seria importante nesse momento voltar para a questão da expansão geográfica interna: a onda de transformações espaciais, bolhas imobiliárias e reestruturações urbanas - que o Brasil agora também se envolve -, nada mais são do que administração da crise, são simulações realizadas através de crédito ou endividamento estatal, que, ao invés de abrir um novo ciclo de expansão, acabam por colocar ainda mais barreiras para a expansão capitalista. Mais uma vez ficam evidentes os limites do desenvolvimento econômico. 


\section{BIBLIOGRAPHY}

ALBAN, Marcus. Crescimento sem emprego. O desenvolvimento capitalista e sua crise contemporânea à luz das revoluções tecnológicas. Salvador: Casa da Qualidade, 1999.

BRENNER, Robert. $O$ boom e a bolha: os Estados Unidos na economia mundial. Editora Record, Rio de Janeiro, 2003.

BUKHARIN, Nicolai. A economia mundial e o imperialismo. São Paulo: Abril Cultural, 1986.

HARVEY, David. A produção capitalista do espaço. São Paulo: Annablume, 2006.

HILFERDING, Rudolf. O capital financeiro. São Paulo: Abril Cultural, 1980.

KURZ, Robert. O retorno de Potemkin: capitalismo de fachada e conflito distributivo na Alemanha. Rio de Janeiro: Paz e Terra, 1993.

LÊNIN, Vladimir I. O desenvolvimento do capitalismo na Rússia. O processo de formação do mercado interno para a grande indústria. São Paulo: Nova Cultura, 1982.

-_-. 0 imperialismo - etapa superior do capitalismo. Campinas: FE/Unicamp, 2011.

LUXEMBURGO, Rosa. A acumulação do capital. São Paulo: Abril Cultural, 1984.

MÉSZÁROS, István. Para além do capital. São Paulo/Campinas: Boitempo/Editora da Unicamp, 2002.

OFFE, Claus. Trabalho e sociedade. Problemas para o futuro da "sociedade do trabalho", v. I - A crise. Rio de Janeiro: Tempo Brasileiro, 1989.

SERRA, José. Ciclos e mudanças estruturais na economia brasileira de após-guerra: a crise recente. Revista de Economia Política, vol. 2/3, julho/setembro de 1982, pp. 111-135.

SMITH, Neil. Desenvolvimento desigual: natureza, capital e a produção de espaço. Rio de Janeiro: Bertrand Brasil, 1988.

SWEEZY, Paul M. Teoria do Desenvolvimento Capitalista. São Paulo: Abril Cultural, 1983.

VIEIRA, Darli Rodrigues. Funções da robótica no processo de acumulação: o caso brasileiro. Petrópolis: Vozes, 1985

\section{NOTES}

1. A obra de Lênin é, na verdade, uma síntese e uma sistematização dos principais argumentos das obras dos outros autores, e é exatamente por isto que consegue ser a mais precisa teoricamente. Como o próprio indica no subtítulo da sua primeira edição, o livro não passava de um "ensaio popular".

2. Mészáros, István. Lembrança de Paul Sweezy. Disponível em: http://resistir.info/mreview/ lembranca_de_paul.html.

3. Quanto a isso, para uma análise das transformações tecnológicas, consulte Vieira (VIEIRA, 1985). Para uma análise teórica mais aprofundada, assim como seus efeitos sobre uma economia nacional, ver Kurz (KURZ, 1993, p.162). 
4. Para uma análise dos efeitos sociais do jobless growth, ver Offe (OFFE, 1989).

5. A expressão é muito explorada por Mészáros (MÉSZÁROS, 2002). Contudo, a expressão é originalmente de Marx, e consta em uma carta enviada a Engels em 1858.

\section{ABSTRACTS}

O artigo tem o objetivo de traçar, em linhas gerais, a relação entre desenvolvimento do capitalismo e crise através de suas expressões espaciais. Argumentando que é possível falar em desenvolvimento capitalista quando há uma expansão espacial absoluta e uma expansão espacial relativa, a crise estrutural do capitalismo é estabelecida quando são ativados os limites dessa expansão, como o esgotamento das fronteiras geográficas ou o desemprego acompanhado de uma expansão do mercado consumidor (jobless growth).

The article aims to demarcate the relationship between capitalist development and crisis through their spatial expressions. Arguing that it is only possible to speak of capitalist development when there are an absolute and relative expansion, therefore the structural crisis of capitalism is established when are reached the limits of this expansion, as the depletion of geographical boundaries or unemployment accompanied by an expanding consumer market (jobless growth).

Sous le plan général, ce texte esquisse le rapport entre le développement capitaliste et la crise capitaliste à travers ses facettes spatiales. Si on peut parler de développement capitaliste dans la mesure où il y a une expansion spatiale absolue et une expansion spatiale relative, la crise structurale du capitalisme sera établie quand les limites de cette expansion sont atteintes, par l'épuisement des frontières géographiques ou le chômage suivi de l'augmentation du marché de la consommation.

\section{INDEX}

Mots-clés: développement, espace, crise structurelle, capitalisme, expansion

Keywords: development, space, structural crisis, capitalism

Palavras-chave: desenvolvimento, espaço, crise estrutural, capitalismo, expansão

\section{AUTHOR}

\section{MAURILIO LIMA BOTELHO}

Doutor em Ciências Sociais pelo CPDA/UFRRJ. Professor Adjunto de Geografia do Departamento de Geociências da UFRRJ 